\title{
Pandemic flu: implications for sexual and reproductive health services
}

\section{Imogen Stephens}

\section{Introduction}

A new pandemic of influenza (flu) has been anticipated for some time: the last actual flu pandemic occurred in 1969/1970. [NB. A pandemic is defined as an epidemic of infectious disease that is spreading through human populations across a large region.] Pandemics of flu occur whenever the prevalent circulating strain of the flu virus changes its antigenic composition significantly, a process known as antigenic shift. When this happens, the 'new' strain is identified as $\mathrm{HxNy}$, where $\mathrm{H}$ and $\mathrm{N}$ refer to the major antigens (haemaglutinin and neuraminidase) and ' $x$ ' and ' $y$ ' refer to their latest molecular shape. The current pandemic flu strain, also known as 'swine flu', is classified as H1N1 and resembles the 'Spanish flu' pandemic strain that caused global mortality during 1918/1919. The case definition for swine flu is well described elsewhere (see Box 1), but a fever of at least $38^{\circ} \mathrm{F}$ is usually considered a prerequisite for diagnosis. However, and perhaps because the swine flu strain is not an entirely new form of the flu virus, up until now the clinical picture of swine flu has been that of a characteristic, but only moderately severe, illness. Certain population groups appear to be more severely affected, however: these include pregnant women, and all people with underlying chronic medical conditions, especially respiratory, and those with immunosuppression. Older people appear to have been less severely affected, perhaps because they have some residual immunity from the tail of the earlier H1N1 pandemic. Children have a high chance of contracting the illness, and the mortality rate, although low overall, has been higher within this age group to date. Death may be due to the primary impact of the virus on respiratory tissue or (more usually) as a consequence of secondary pneumonia. Antiviral medication is available for those with confirmed swine flu; however, its main impact is to shorten the duration of illness, rather than its severity. A mass immunisation programme is planned in the UK from October 2009: this will itself pose major organisational challenges to the National Health Service. Frontline health care workers will be offered this vaccine alongside other priority groups.

\section{Pandemic progression}

Flu pandemics do not necessarily follow the typical seasonal pattern of usual 'seasonal' flu. So it is entirely predictable that the current swine flu pandemic developed during the summer season in the northern hemisphere. However, a major concern for health service planners is that the viral strain may continue to modify itself in a more minor fashion (a process known as antigenic drift) and, in doing so, may develop into a clinically more severe illness as the pandemic progresses globally. Over the summer we have seen a significant drop in swine flu cases globally, but we can expect subsequent waves of the pandemic over the autumn and winter months. For this reason it makes sense

J Fam Plann Reprod Health Care 2009; 35(4): 215-216

Department of Health South East, Guildford, UK

Imogen Stephens, MRCOG, FFSRH, FFPH, Consultant in Public Health Medicine and Associate Editor, Journal of Family Planning and Reproductive Health Care

Correspondence to: Dr Imogen Stephens.

E-mail: i.stephens@nhs.net
Box 1: Useful links for current information on pandemic flu

NHS Choices: www.nhs.uk Directgov: www.direct.gov.uk

National Pandemic Flu Service: http://www.direct.gov.uk/en/ groups/dg_digitalassets/@dg/@en/documents/digitalasset/dg_1 78842.htm

Health Protection Agency (HPA): www.hpa.org.uk

World Health Organization (WHO): http://www.who.int/csr/ disease/swineflu/en/index.html

NHS Networks (guidance for local planners): http://www. networks.nhs.uk/uploads/08/03/guidance_to_local_planners.pdf

for all clinicians and service managers to ensure their services continue to run smoothly throughout any further, and potentially more serious, waves of the pandemic.

\section{National Flu Pandemic Service}

The National Pandemic Flu Service (see Box 1) is a new online service that will assess symptoms and relieve pressure on the primary care system during future epidemic waves. If required, it will provide an authorisation number that can be used to collect antiviral medication from a local collection point. For those individuals who do not have Internet access, the same service can be accessed by telephoning 08001513100 .

\section{Implications for clinical services}

Swine flu will have potentially serious implications for clinic staff in both general practice-based and communitybased services, and for clients. Some of the potential impacts are listed below.

\section{Infection control}

- Hand washing: hand gel should be available and highly visible at all entrances and exits, and its use encouraged at all times for clients and all staff.

- 'Catch It, Bin It, Kill It': ensure that clients and staff abide by this campaign, by using and disposing of tissues quickly and responsibly.

- Cleaning of hard services: particular attention should be paid to cleaning and hygiene of door handles, clinic surfaces and keyboards.

- Local policies: work closely with your infection control co-ordinator, and follow all local policies.

\section{Staff}

- Sickness absence: planning projections are that $10-12 \%$ of the local population will become ill each week during epidemic peaks; each wave is expected to last $12-15$ weeks; expect $25-50 \%$ staff to be absent from work sick during each epidemic wave; smaller organisations are less robust so should plan for 30-35\% absence rates at peak periods of the epidemic.

- Mass vaccination campaign: primary and community staff will be offered the vaccine as a priority group, and should therefore obtain fairly rapid immunity. An additional consideration is likely to be that primary and community sexual and reproductive health (SRH) staff have key clinical skills and may need to be redeployed to enable the mass vaccination programme to be delivered successfully. 
- Caring responsibilities: staff may need to stay away from work to care for young children and elderly relatives, if affected. There is no need for asymptomatic contacts to stay away from work for other reasons.

- School closure: if subsequent epidemic waves become severe; it is probable that schools will be closed, either due to staffing problems or as an emergency response to reduce further spread; this will have a significant impact on the ability of many staff to attend work.

- Administrative staff: this is a key function for all services, and it will be essential to prioritise certain administrative functions, such as telephone cover and appointment systems.

- Clinical staff: all non-essential clinical work should be reviewed and, if necessary, deferred to enable as much cross-cover as possible and to maintain a basic level of essential service to clients. Emergency contraception provision, in particular, should be maintained, and good links developed with local pharmacies, which may provide an over-the-counter alternative.

- Training: some additional training may be necessary to help others provide cross-cover. A training needs analysis would help all services to plan and deliver this.

\section{Clients}

- Clients may be unable to travel to the clinic, due to illness or travel restrictions.

- Clients may be unable to keep appointments, and then be at increased risk of unplanned pregnancy if supplies of contraception were to run out. This can be minimised by good communication with clients, by careful monitoring, by encouraging and allowing repeat prescriptions and the use of 'flu friends' to collect supplies.

- In exceptional circumstances, where clients are unable to attend clinical services of any kind, and a 'flu friend' is not available, it may be possible to post a pack of oral contraceptives. Telephone consent should be obtained, as confidentiality issues may otherwise arise.

- Antivirals and side effects: vomiting has been reported as a side effect of Tamiflu ${ }^{\circledR}$, especially in young people. This may result in an increased need for emergency contraception.

\section{Communications}

- Take all reasonable steps to ensure employees are aware that if they have swine flu symptoms, or think they have, they should not come to work until up to 5 days after the onset of symptoms.

- Ensure that any alterations to services are well publicised, through clear posters and instructions on telephone answering machines.

- Develop close links with commissioning organisations, with related services, and with local pharmacies.

- Keep in close contact with information sources, locally, nationally and internationally if necessary (see Box 1).

\section{Services}

- Consider other options to keep services and supplies available: e.g. links with local pharmacies, independent sector treatment centres or other local SRH services.

- Maximise the use of long-acting contraceptive methods, where possible and feasible.

- Business continuity planning: useful checklists are available to help with this (see Box 1).

\section{Disclaimer}

The views expressed in this Commentary are those of the author herself, and not necessarily those of her employing organisation.

Statements on funding and competing interests

Funding None identified.

Competing interests None identified.

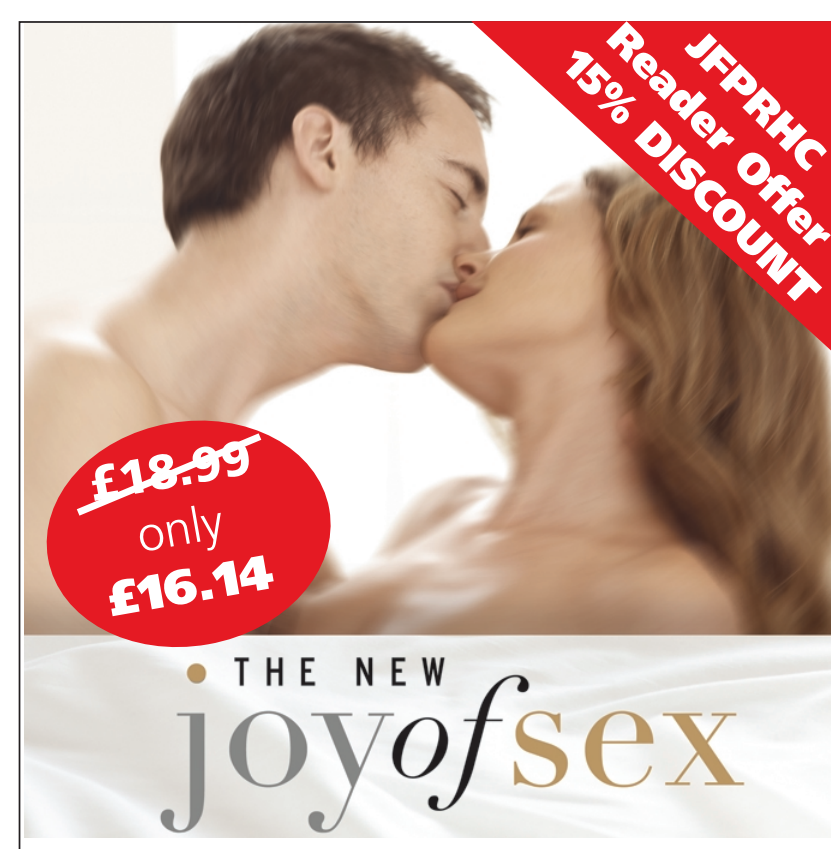

\section{The New Joy of Sex and the two mini gift books - ideal for your Clinic Library or, indeed, Christmas Presents!}

As a champion of trusting, loving relationships, this groundbreaking book advocates mutual respect and tenderness between lovers. A bestseller since it was first published in 1972, Alex Comfort's classic work celebrated human physical intimacy with such authority and clarity that a whole generation felt empowered to enjoy sex. This new edition of The Joy of Sex, fully revised and updated by the Journal of Family Planning and Reproductive Health Care's own consumer correspondent and relationship psychologist, Susan Quilliam, contains over 40 new entries, bringing Comfort's original, frank advice up to date for a modern readership.

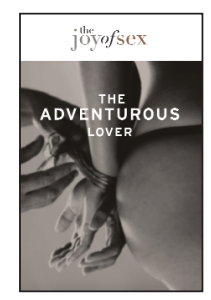

With thought-provoking text by Susan Quilliam, The Adventurous Lover will help readers to explore their own and their partner's desires and add an extra dimension to their intimate lives. This book is the perfect companion for those times when you need ideas for what to do and guidelines for how to do it, for when you need arousing inspiration to kick-start your adrenalin, and for when you need confidence to push the boundaries, and then push them a little further.

\section{£895 $f 7.64$}

Passion may provide the initial impulse for sex, but it's romance that will keep love alive. And although it need not always be gentle,

underpinning even the most energetic of sex, there should always be an element of romance. Romantic lovers are in tune with their partner's feelings and desires. With the simple additions of sensitive techniques and stimulation for you and your partner's imagination, relationships can become even deeper and physical intimacy can increase tenfold. With inspirational text by Susan Quilliam, The Romantic Lover inspires the confidence necessary to express loving emotions in the most powerful of ways and to add new depth to your levels of intimacy.

\section{f8seg 57.64}

Order online at www.octopusbooks.co.uk and enter J0S100 when you check out to receive a $15 \%$ DISCOUNT. 